\title{
INTELECTUAIS, POLITICA E ARTE: SOBRE O JOGO DE RESSIGNIFICAÇÃO DA AUTONOMIA ARTÍSTICA
}

\section{INTELLECTUALS, POLITICS AND ART: ON THE REDEFINI- TION OF ARTISTIC AUTONOMY}

\author{
Kadma Marques Rodrigues* \\ Diego Soares Rebouças*
}

\section{Introdução}

O século XIX inaugurou mudanças significativas em diversos campos de ação social. Dentre estes, o presente artigo considera o campo intelectual como espaço social abrangente e transversal que se efetiva nos vínculos estabelecidos entre a produção de conhecimento disciplinar científico, o campo da cultura e aquele da arte. Assumindo parte ativa nessas mudanças, o campo intelectual subsidiou o processo de autonomização do campo das artes, e por consequência, agenciou o reconhecimento de imperativos que passaram a conformar o campo artístico, a exemplo daquele da centralidade da liberdade criadora e de elaboração da poética de seus produtores.
Tal contexto proporcionou as condições sociais de possibilidade para a emergência de uma nova forma de intelectualidade, diferenciada daquela que servira diretamente aos interesses do Estado, da política ou do Direito, corporificando-se em uma malha de agentes, a exemplo de escritores, críticos de arte e dos próprios artistas. Discursivamente, eles alicerçaram a reformulação de disposições coletivas na produção, na distribuição, na circulação de práticas e de bens culturais e artísticos como marca da modernidade.

Rompendo com a hegemonia da Igreja católica e da aristocracia - principais liames de influência externa na produção artística durante a Idade Média - os agentes do campo intelectual, na passagem do sé-

\footnotetext{
* Doutora em Sociologia e docente no Programa de Pós-Graduação em Sociologia na Universidade Estadual do Ceará - UECE - (Fortaleza/CE/BR). E-mail: kadmamarques@yahoo.com.br.

** Mestre em Comunicação pela Universidade Federal do Ceará - UFC - (Fortaleza/CE/BR). E-mail: diegosoaresreboucas@gmail.com.br.
} 
culo XVIII para o XIX, lançaram-se à conformação de um cenário de maior autonomia para os produtores de bens simbólicos.

Naquele momento histórico em que ainda repercutiam os efeitos da Revolução Industrial, o sistema simbólico das artes acompanhou o surgimento da fotografia, mediante reestruturação dos cânones da figuração, até então formatada para atender a demandas sociais de produtos artísticos. Questionando a representação plástica advinda de gerações anteriores, o campo artístico assumiu como paradigma dominante uma produção cuja ênfase recaía sobre a subjetividade e a interioridade do gênio criador na arte moderna. Mais tarde, a formulação discursiva acerca dessa tendência à ruptura com a tradição será igualmente adequada à interpretação dos processos desencadeados pela sociedade de consumo e pela chamada arte contemporânea, a qual leva ao limite as possibilidades da representação "autônoma" e performativa na criação artística.

Assim ligados, o conceito de modernidade e a prática estética fundem-se no que vai se tornar a arte moderna.... Situada, a arte moderna é característica de um período econômico bem definido, o da era industrial, de seu desenvolvimento, de seu resultado extremo em sociedade de consumo. (CAUQUELIN, 2005, p. 27)

Para Pierre Bourdieu (1968), em cada momento histórico, a produção cultural é afetada significativamente tanto pela natureza das relações sociais, quanto pela posição do artista na estrutura do campo intelectual. Partindo desta perspectiva, esse artigo busca problematizar as transformações do sistema cultural no Brasil a partir das recentes repercussões políticas que envolvem o universo das artes plásticas no país. Para tanto, põe em destaque o papel de artistas no campo intelectual, em sincronia com aquele de outros agentes envolvidos, a exemplo de críticos e curadores, os quais compõem linhas de força do campo intelectual, como Bourdieu (1968) propõe.

No presente trabalho, é preciso considerar não apenas a dimensão social do campo artístico na segunda metade do século $\mathrm{XX}$, mas também as mudanças nos papéis e a influência que cada um dos citados agentes passa a desempenhar na ordem comunicacional e mercadológica que configurou suas formas contemporâneas. Nessa perspectiva, é preciso ainda esmiuçar a relação que se configura entre campo artístico e intelectual mediante a emergência de figuras como a do intelectual especifico, proposta por Michel Foucault (2011).

De fato, o contexto oferecido pelos movimentos libertários dos anos 60 comporta uma mudança radical na relação dos intelectuais não só com o pensamento crítico e reflexivo (esfera do saber), mas também com os modos de intervenção política (esfera da ação). Até então, “o intelectual dizia a verdade àqueles que ainda não a viam e em nome daqueles que não podiam dizê-la, reunindo os atributos da eloquência (para dizer) diante das massas e da consciência (para revelar) os problemas de seu tempo" (FOUCAULT, 2011, p.70-71).

De fato, o intelectual específico foucaultiano assinala não apenas a ruptura com a crença na eficácia dos metadiscursos da grande teoria, abstrata e com pretensões à universalidade (representada pelo modelo paradigmático do filósofo francês Jean -Paul Sartre). Sua postura também implica a consequente adesão a espaços circunscritos da experiência social e ao modo como surgem questões específicas que dele emer- 
gem, integrando-as àquelas que sobressaem na esfera pública. Assim, se

Os intelectuais específicos estão à mercê de serem manipulados pelo mercado, pela universidade, pelo partido etc., resta a eles tomarem para si outra função. Ao contrário dos intelectuais universais, que prezam por uma nova filosofia, uma nova visão do mundo, uma mudança global, os intelectuais específicos cumprem um papel político cada vez maior. 0 que eles pretendem é modificar o regime de produção do saber, de maneira específica e com participação política ativa. Eles são os intelectuais que saem detrás do escritório e assumem posições práticas ${ }^{1}$.

Assim, como agentes políticos que contribuem para a reconfiguração do sistema de poder que estrutura hierarquicamente os diversos campos culturais, os intelectuais específicos acabaram por revelar o papel exercido anteriormente pelos intelectuais universais no exercício do monopólio discursivo, o qual descredenciou historicamente a interpretação dos agentes sociais que vivenciam problemas práticos.

Mesmo no campo artístico, o qual teve sua constituição calcada na atividade do artista criador, as chaves de interpretação das dinâmicas do campo foram forjadas ao longo do tempo pelo discurso intelectualizado da crítica de arte, bem como do conhecimento disciplinar da Filosofia, da História, da Sociologia e da Antropologia. Assim, "a inteligência academicamente dominante não pode reconhecer [a inteligência artística prática, que articula problemas formais e disposições incorporadas] sem transfigurá-la em inteligência acadêmica”. (Bourdieu, 2013, p. 124)

Portanto, no século XX, a presença do intelectual específıco implica uma guinada epistemológica potencial na própria função desse agente no campo intelectual, não só por sua relação diferenciada com a teoria, mas também com outros campos de ação social, cuja dinâmica vê-se radicalmente impactada:

É por isso que a teoria não expressará, não traduzirá, não se aplicará numa prática; ela é uma prática. Mas local e regional... não totalizadora. Luta contra o poder, luta para fazê-lo aparecer e feri-lo onde ele é mais invisível e insidioso. Luta não para uma "tomada de consciência”... mas para a destruição progressiva e a tomada do poder ao lado de todos aqueles que lutam por ela, e não na retaguarda, para esclarecê-los. Uma "teoria" é o sistema regional dessa luta. (FOUCAULT, 2011, p. 71)

Assim, no que concerne ao campo das artes plásticas, algumas questões se impõem: atualmente, quais as especificidades que marcam o ofício do trabalho intelectual no campo artístico? Quais são seus agentes? Como se constrói o conceito de autonomia artística e como seus intelectuais específicos se posicionam? Quais seus vínculos com a esfera da comunicação, da política e do mercado de artes?

Para responder a tais questões, é preciso considerar ao menos três aspectos que demarcam a contribuição dos intelectuais, universalistas e específıcos, para a passagem da arte moderna à chamada arte con-

1. Fonte: http://colunastortas.com.br/o-intelectual-especifico-segundo-foucault/ 
temporânea: (i) a relação autorreferenciada das artes plásticas, mediante a criação de uma lógica social própria que orienta a produção de formas artísticas, refrata conexões com o campo da política; (ii) os meios de comunicação em uma era na qual os avanços tecnológicos potencializam a superação de fronteiras espaço-temporais afetam a construção da identidade do artista, sua representatividade, bem como a de seus processos criativos e a das formas de consumo de suas obras; e (iii) a relação do campo com o mercado, o qual condiciona novas modalidades de trabalho artístico e do perfil de consumidores.

\section{Sobre a invenção dos intelectuais e do campo artístico}

Dentre os efeitos que podem ser associados à Revolução Industrial, acham-se a mudança de hábitos na vida social e o surgimento de uma nova classe - a burguesia. Tais mudanças repercutiram especialmente no sistema de produção de bens simbólicos, o que aportou na reconfiguração de papéis das instituições e dos agentes envolvidos.

A necessidade de afirmação do lugar social do artista na cultura burguesa - cuja hegemonia tinha por base a posse de meios econômicos e não mais o mecanismo de hereditariedade que caracterizou a sociedade aristocrática - levou a produção artística a fundar suas bases de legitimação na lógica da competência propriamente artística.

Nesse cenário, a convergência entre campo intelectual e artístico como esferas sociais relativamente autônomas em processo semelhante de configuração manifestou-se não só por meio da intervenção de intelectuais na reelaboração dos cânones que determinavam as artes de modelo aristocrático, mas também por sua oposição aos escritores do século XVIII que, submissos ao Estado, restringiam-se a provocar divertimento. Assim,

a crítica de arte afirma sua autonomia, torna-se um gênero específico. Caminha na direção da exploração de critérios próprios da picturalidade e deixa o domínio das avaliações normativas que concernem a formatos, temas, adequações das figuras ao tema... (em suma) o tratamento iconográfico que era a essência da crítica oficial. (CAUQUELIN, 2005, p. 42)

É, então, pela autoridade obtida como pensadores e artistas puros que intelectuais, a exemplo do escritor Émile Zola, puderam intervir no campo político, mas com outras armas que não as dos homens de ação aquelas do discurso universalizante, libertário, desinteressado. De acordo com Bourdieu (1996) “é sem dúvida com o século XIX e o movimento romântico que começa o movimento de libertação da intenção criadora, que vai encontrar nas teorias da arte pela arte sua primeira afırmação sistemática” (p. 109).

É importante ressaltar ainda que, com o advento da fotografia, o recuo da figuração ao longo da primeira metade do século XX e a emergência de modos abstratos de expressão pictórica acentua-se a relação autorreferenciada das vanguardas artísticas com a história das formas plásticas. Estes aspectos, dentre outros, concorreram para a criação da lógica social própria (cognitiva e perceptiva) que orienta a produção e o consumo das imagens artísticas, as quais se distanciam da figuração documental fotográfica.

Nessa passagem, o crítico que despontou no século XIX como elemento mediador fundamental da oposição sustentada 
pela perspectiva vanguardista em relação à arte de Estado constituiu as balizas do trabalho especializado que teria lugar no século seguinte. Assim, no início do século XX, o trabalho especializado conduzido pela crítica de arte parecia ainda encontrar convergência entre as aspirações universalistas do campo intelectual, o discurso formulado por artistas que "teorizavam" sobre sua própria prática e a ruptura que se radicalizava entre a experiência visual cotidiana e as formas abstratas puras. De todo modo,

... (o crítico) tece o vínculo entre o mundo da arte e o dos aficionados da arte; entretém o público com problemas propriamente pictóricos e contribui para formar, na opinião pública, a imagem do artista "moderno", que ela projeta no futuro como "vanguarda". (CAUQUELIN, 2005, p. 42-43)

Para compreender as dinâmicas sociais e o papel desempenhado por este segmento, tomado como representante do campo intelectual, Bourdieu (2014) lembra que é preciso realizar uma análise crítica do próprio espaço social da crítica de arte.

Ou seja, (entender) qual era a posição desse discurso no espaço dos discursos, e qual era a posição do produtor desse discurso no espaço dos produtores desses discursos. Um documento, seja qual for e isso é verdade, creio, para todo documento histórico, é uma tomada de posição num espaço que tem sentido, de um lado, por referência ao espaço das tomadas de posição homólogas, e de outro, por referência ao espaço das posições cuja expressão são essas tomadas de posição. (BOURDIEU, 2014, p. 126)

Portanto, com o advento do que se convencionou chamar modernidade, o campo artístico configurou-se como espaço social de batalha intelectual, povoado pela dissimetria entre críticos que têm assumido diferentes posições e tomadas de posição. 0 exercício da autonomia que causa escândalo, provocado pela transgressão de valores éticos e/ou estéticos nesta ou naquela obra de arte moderna, levava assim a disposição do crítico a assumir expressões diferenciadas, desde a muda indignação até a esmiuçar a história que o quadro conta de modo a produzir uma peça literária cuja ambição fınal seria a de substituir o próprio quadro alvo do discurso especializado; ou ainda a estabelecer com o pintor uma relação de cumplicidade e empatia, revelando em qual recorte da história da pintura aquele quadro se situava. (BOURDIEU, 2014).

Nesse sentido, como elemento que integra as condições sociais de possibilidade de recepção da obra plástica, o crítico de arte constituiu historicamente parte da audiência especializada que concorre para a objetivação social da relação artista-obra -público. Assim, por meio de sua produção interpretativo-discursiva, ele concorre para a definição coletiva da obra ao explicitar suas linhas estruturais, concorrendo ou convergindo com o sentido de cada projeto criador, ou seja, com a ideia em certa medida consciente que o artista tem de sua proposta (BOURDIEU, 2014).

Embora as revoluções simbólicas provocadas pela produção artística moderna e contemporânea tenham obrigado a crítica de arte à reelaboração recorrente de chaves interpretativas das lógicas que subsidiam sua atividade intelectual, tal defasagem não elimina o fato de que o trabalho do crítico contribuiu, na passagem do século XIX ao século XX, para a formação da eXperiência sensível de um público crescente, mais complexo e heterogêneo. 
Na segunda metade do século XX, a intensificação de pesquisas formais conduziu as dinâmicas do campo da abstração na arte à posterior superação desta pela ruptura com o suporte tradicional. Tal fato abriu conexões entre arte e vida que deram lugar à body art, às performances, às obras conceituais e outras propostas, provocando o fortalecimento da dimensão discursiva $\mathrm{e}$ performática na atividade artística.

Em um momento no qual ocorre o deslocamento do eixo fundamental que concretiza os processos de criação artísticos atuais - do estatuto moderno ao contemporâneo, do regime de produtos àquele regido por processos, da espacialidade pictórica à temporalidade que se impõe nas obras performáticas - a dimensão discursiva (conceitual ou comunicacional) das formas plásticas convertese em seu elemento basilar. Nesse contexto,

'estado contemporâneo' significa que esse sistema não é mais aquele que prevaleceu até recentemente; ele é o produto de uma alteração de estrutura de tal ordem que não se podem mais julgar nem as obras, nem a produção delas de acordo com o antigo sistema. (CAUQUELIN, 2005, p.15)

Assim, se modernamente a dimensão performativa do campo artístico se manifestava no fato de que para viver de arte era necessário inventar uma arte de viver, propriamente artística, contemporaneamente tal dimensão agudiza-se, estruturando internamente os projetos criadores. Em face desta mudança, os públicos são alçados à condição de cocriadores e novos agentes, a exemplo dos curadores, emergem no campo, igualmente imbuídos do exercício de uma função "criativa" metaconceitual, a qual faz recuar ao segundo plano tanto o artista, quanto o crítico profissional.
A maneira de mostrar uma seleção de obras de arte reflete diretamente a curadoria de qualquer exposição, pois é por meio da montagem, além, naturalmente, das obras selecionadas, que o curador vai expor suas ideias. Seja estabelecendo relações formais ou conceituais entre as peças expostas, seja localizando-as de forma estratégica no espaço, a disposição das obras pode resultar numa exposição eficaz, onde os diálogos propostos facilitam a compreensão dos objetos expostos, ou num labirinto de ideias onde o visitante se sente perdido. (RAMOS, 2010, p. 15)

Logo, reunindo diferentes competências (aquelas do colecionador, do crítico, do artista, do marchand, da técnica expográfica), o curador passa a compor hierarquicamente o conjunto de práticas e de agentes que integram o campo artístico. Neste contexto, sobretudo são afetados a representação e os modos de viver dos artistas "nas derradeiras etapas de transformação do regime industrial clássico em regime de puro consumo" (CAUQUELIN, 2005, p. 30).

Assim, se a industrialização alimentou a mecanização da vida com farta difusão de produtos, a partir dos anos 1980, os contornos globais da chamada indústria cultural (BUENO, 2010) converteu o sujeito comum em alvo privilegiado do consumismo de demandas inventadas que desconhecem limites de tempo ou lugar. Desse modo, indústria cultural e globalização são conceitos que implicam, quase que imediatamente, as categorias comunicação de massa e sociedade da informação. Estes são sintomas e, ao mesmo tempo, causas das mudanças nos padrões de visualidade inaugurados pela modernidade, mas cujos desdobramentos ainda testemunhamos nos dias atuais.

Ademais, segundo Muniz Sodré (1996), a nova configuração comunicacional que 
mediatiza as relações entre as instituições sociais também estabelece uma estreita ligação com a economia de mercado "que se impôs na modernidade ocidental como forma única de organização econômica e aparece como substrato iniludível da cultura contemporânea" (SODRÉ, 1996, p. 8).

A sociedade de mercado contemporânea se apresenta, dessa maneira, como um domínio fértil para múltiplas reflexões de cunho sociológico. Mas como os intelectuais que representam o campo das artes plásticas se relacionam, por um lado, com a esfera da comunicação, e por outro, com aquela das novas dinâmicas mercadológicas que conformam novos hábitos de consumo?

\section{Arte contemporânea e mercado: media- ções comunicacionais}

Na primeira metade do século passado, Marshall McLuhan $(1964 ; 1971$; 1977) lançou as bases para a formulação de estudos acerca da mútua imbricação entre o advento das novas tecnologias e a sociedade pós-revolução industrial. 0 autor cunhou a noção de aldeia global com o intuito de dar a ver os processos que se encontravam em curso para instauração de um mundo permanentemente conectado.

Por sua vez, na década de 40, Paul Lazarsfeld $(1944 ; 1955)$ se opôs à ideia de uma imposição total das mensagens midiáticas a diferentes públicos. Para ele, a eficácia dos meios de comunicação de massa estaria associada à ação do que chamou formadores ou líderes de opinião, capazes de influenciar no processo de tomada de decisão (teoria do two step flow of communications).

No âmbito de tais elaborações teóricas, destacam-se aquelas que buscaram apreender as dinâmicas sociais desencadeadas pela chamada comunicação de massa a partir de certa convergência entre os campos da comunicação e das artes. Tal convergência provocou impactos consideráveis não apenas em representações da arte e do artista contemporâneo, mas também nas lógicas formais dos seus processos de criação plástica e notadamente nas estruturas de distribuição / circulação de valores que configuram o mercado de arte. De acordo com Santaella:

a coincidência dos meios de comunicação com os meios de produção de arte foi tornando as relações entre ambas, comunicações e artes, cada vez mais intrincadas. Os artistas foram se apropriando sem reservas desses meios para as suas criações. Isso se acentuou quando começaram a surgir, por volta dos anos 1970-80, novos meios de produção, distribuição e consumo comunicacionais instauradores do que tenho chamado de cultura das mídias que apresenta uma lógica distinta da comunicação de massas (2005, p. 13)

Atualmente, no âmbito das artes plásticas, é possível destacar pelo menos dois aspectos dessa convergência: o uso dos suportes comunicacionais como meios da produção artística, de um lado - a exemplo das formas contemporâneas da arte, que se instalam no domínio das novas mídias e tecnologias -, e/ou, por outro lado, como canais de circulação dessa mesma produção, tornando-se plataformas conectadas em redes de instituições e de agentes diversos (galeristas, curadores, críticos, colecionadores, marchands) encarregados da divulgação de seus trabalhos e/ou de seus perfis:

Em princípio, e não sem contradições, a obra e o artista serão "tratados" pela rede de comunicação simultaneamente (sem eles, a rede não tem razão de ser) mas também como um produto da rede (sem a rede, nem 
a obra nem o artista têm existência visível). São as noções-princípios da comunicação... que darão conta de seu estatuto contemporâneo. (CAUQUELIN, 2005, p. 73)

A sociedade da comunicação, centrada na cultura dos meios, vem assim cadenciando certa equivalência entre ser e aparecer nos meios de comunicação. Sendo assim, os mecanismos de legitimação passaram às mãos de outros agentes, instâncias e instituições. Tudo o que é elevado à visualidade passa a ter "um lugar" e a existir. Esse aspecto está mais intimamente ligado à questão da autonomia da arte tratada neste artigo. A velocidade na transmissão de informações imposta pela rede (impessoal, infınita, heterogênea e supostamente não-hierárquica) parece servir à

... renovação permanente de movimentos ou de artistas... (e tal movimento) pode estar ligado não a uma intenção particular, mas, sim, a uma consequência do próprio sistema. Diferentemente das vanguardas da arte moderna, que se organizavam contra o mercado de arte oficial para preservar a autonomia da arte, no caso da arte contemporânea pretende-se uma absorção da autonomia pela comunicação. (CAUQUELIN, 2005, p. 76)

Assim, os artistas que são inseridos ou aderem ao uso das novas formas de comunicação tais como plataformas virtuais usufruem de seu potencial imersivo e de ubiquidade junto a diferentes públicos. Porém, eles também sofrem os efeitos da necessidade de renovação e de singularização recorrente das imagens que circulam, a fim de atingir um público de arte seleto e especializado. Desse modo, o uso do ciberespaço se torna uma condição imprescindível ao métier artístico contemporâneo, mas também impõe a este seu ritmo.
0 próprio $b \log$, a princípio destinado à publicização de manifestações pessoais, servindo não poucas vezes de diários íntimos, tornaram-se fontes de informações e ferramentas do trabalho artístico. Essa ferramenta - o blog - permite uma aproximação mais satisfatória, ainda que informal, com os públicos do que o site, a página oficial. Nesse sentido, esses meios passaram a compor formas de divulgação de obras e de projetos da produção artística, mas também se tornaram espaço para tomada pública de posição e para a manifestação política dos artistas.

No mesmo sentido, também podem ser encontrados com frequência nas redes sociais perfis e contas de outros profissionais envolvidos com ofícios ligados às artes: curadores e curadoras utilizam suas contas de Instagram para evidenciarem seus últimos trabalhos. Eles divulgam assim as exposições que assinam, evidenciando as parcerias e preferências que constituem o percurso investigativo de construção de projetos curatoriais no âmbito do campo artístico.

A função do curador assume, assim, contornos eminentemente conceituais, conferindo organicidade ao campo, tecido pelo trabalho intelectual que rivaliza em importância com a atividade do artista. Assim, “... o curador (não é um) mero organizador de exposições (...) mas (um) indivíduo com capacidade crítica (capaz) de reposicionar o nosso entendimento sobre a arte num tour de force intelectual, espacial e visual" (RAMOS, 2010, p. 154).

Do mesmo modo, críticos e críticas de arte, na baila, usam seus perfis no Twitter para divulgarem instantaneamente os links dos últimos artigos que publicaram; produtores culturais e profissionais da área de expografia, como arquitetos e designers especializados, mantêm igualmente sites na internet com amostras das últimas exposi- 
ções que assinaram.

As reconfigurações evidenciadas por este panorama impõem algumas questões: dentre os intelectuais que representam as dinâmicas do campo da arte, qual o lugar do artista face ao recuo sofrido pela representatividade social do crítico e a emergência do curador? E como a multiplicação de elementos mediadores, associada à emergência das novas tecnologias e aos seus efeitos de reestruturação lógica dos mercados de arte, afeta a relativa autonomia da elaboração de poéticas artísticas?

\section{Autonomia artística e engajamento políti- co: as atribulações de um estatuto}

A emergência de um valor e de uma lógica própria, urdida conjuntamente por artistas e intelectuais, teve importância fundamental no processo de autonomização do campo artístico. Porém, nesta perspectiva, não menos importante foi a tendência à singularização que distinguiu socialmente a figura do artista por meio do trabalho demiúrgico de depuração formal, crescentemente autorreferencial, que caracteriza obras modernas (BOURDIEU, 1996). Tal tendência, materializada na realização de um estilo singular, nutriu uma disposição criativa por parte dos movimentos vanguardistas que se diferenciava daquela, presente anteriormente no trabalho de pintores acadêmicos. Os primeiros sobressaíram pela negação a filiações estéticas; enquanto os últimos valiam-se destas para realizar uma espécie de continuidade elogiosa (HEINICH, 2001).

Ocorre que, na passagem da arte moderna à sua configuração contemporânea, a produção artística sofreu um deslocamento de seu eixo central, baseado sobre a singularidade do par artista-obra: passa-se do embasamento no produto para aquele assentado no processo. Como consequência, o artista assiste tanto à multiplicação de agentes mediadores, quanto à dissolução do elemento que o distinguia socialmente - a exclusividade na representação da atividade criadora. Neste ponto, talvez seja esclarecedor questionar tais mudanças a partir das considerações de Cauquelin (2005) acerca do declínio do modelo oferecido pela arte moderna:

Podemos nos perguntar se a arte não
contemporânea - a do século XIX e do
princípio do século XX - tinha quali-
dades tão fantásticas do ponto de vista
da inovação, do status econômico e do
reconhecimento do público, a ponto de
parecer oportuno, até mesmo necessá-
rio, colocá-la sobre um pedestal e cho-
rar seu desaparecimento. (p. 17)

A fim de aquilatar as repercussões das transformações causadas pelo advento da chamada arte contemporânea, é preciso retomar as polêmicas dessacralizantes conduzidas pelo próprio meio artístico, a exemplo daquela encabeçada pelos ready-mades de Duchamp, na segunda década do século XX; passando pela performance de Joseph Beuys com sua lebre morta; e ainda pela atuação do Grupo Fluxus, orquestrado pela expertise criativa de Maciunas e Flynt, na década de 60 do mesmo século. Estes e outros eventos fulcrais para a afirmação da condição contemporânea do campo artístico trouxeram a marca da insurgência contra os elementos que haviam demarcado o próprio campo a partir do referencial moderno.

Em termos de condicionantes externos, a superação social dos marcos da modernidade cultural pode ser percebida sinteticamente a partir dos seguintes elementos: se o mercado de arte moderna fixava estilos, ameaçando em certa medida a autonomia da criação ar- 
tística, tal ameaça acentuou-se com o mercado organizado em rede mundial, que engloba o artista como um dos pontos; a valorização do processo em detrimento da obra em sua materialidade envolve frequentemente o público no trabalho de concretização da obra, levando-o a dividir com o artista o lugar de agente criador; a emergência de novos agentes no campo, a exemplo do curador, converte o trabalho do artista em peça de seu projeto de criação conceitual (diferentemente do discurso do crítico ou de certa produção disciplinar nas ciências humanas, as quais corroboravam a celebração do artista moderno); a arquitetura dos lugares de exposição que, antes por sua estrutura do que pelas obras que abriga, passa a atrair o público, elevando seus criadores à condição de arquitetos-estrela; ou o registro de obras efêmeras que, saindo voluntariamente do espaço museal para compor a complexidade excitante das cidades, retornam a ele sob a forma de fantasmagorias da potência manifesta no encontro com o público.

Neste contexto, testemunhamos o processo de apagamento social da figura do artista, delineado pelo campo artístico moderno, que parece ter sido integrado como um dentre outros domínios do universo difuso dos criadores, no qual o artista plástico converte-se em elemento periférico que gravita em torno de um centro ocupado por criadores mais afınados com a dinâmica do mercado pós-industrial globalizado.

Por meio da análise sociológica, é preciso, antes de mais nada, desdobrar a noção de autonomia artística a partir das atribuições históricas que delinearam o espaço de criação do trabalho do artista: 1) ele deixa de estar subordinado diretamente a encomendas, bem como às orientações dos mecenas; 2) ele se empenha em atender aos imperativos de expressão estilística frente aos interesses de um sistema industrial que convertia obras em mercadoria; 3) e, por fim, busca assumir papel profissional ativo no âmbito de um sistema comunicacional que estrutura o campo artístico em forma de rede mundial.

A fim de considerar o campo artístico como contexto de exercício profissional à semelhança do que fez Howard Becker (2010), é preciso partir da noção de ação coletiva. Esta atravessa todo o tecido social, especificando-se na atividade do artista, abordada como profissão. Esta se converte em um conceito operatório que liga obra e contexto institucional, prático e técnico (ou sociotécnico), evidenciando a rede de indivíduos cuja atividade cooperada produz o tipo de obras que subsidiam a notoriedade do artista, graças ao conhecimento partilhado dos meios convencionais de trabalho.

Desse modo, os mundos da arte concorrem para o reconhecimento não só do artista que conhece e molda convenções, mas também dos agentes que integram os processos de difusão: os curadores, os galeristas, os editores, os críticos, os produtores culturais, os colecionadores/compradores, as instituições e o próprio público. A perspectiva adotada é assim diametralmente oposta àquela da tradição dominante na sociologia da arte. Esta singularizou artista e obra, colocando-os no centro de análises que invisibilizaram os demais agentes que atuam cotidianamente no campo da arte.

Conferir ênfase à rede de relações de cooperação que estruturam o lugar ocupado pelo artista e por sua obra favorece a compreensão das ambivalências que caracterizam a disposição do artista na atualidade, sobretudo, no que concerne ao modo como se articulam nas obras projeto criador e mobilização política. É certo que a arte contemporânea traz uma interessante dimensão temporalizada e coletiva ao primeiro plano, tornando obsoletas as inter- 
pretações centradas na individualidade do artista genial ou na estabilidade da obra.

As questões suscitadas pela relação entre a particularidade da obra contemporânea e seu entorno demanda então que a análise sociológica parta da obra in situ e da observação do conjunto de elementos que compõe seu entorno, naquilo que Benghosi e Paris nomeiam contexto de manutenção. Pois, sendo singular em sua "materialidade”, a obra implica a mobilização de competências sociotécnicas específicas, as quais potencializem seus efeitos sobre os públicos.

A exposição de tais obras requer saber arbitrar entre as exigências da obra e múltiplas limitações, tais como as normas de segurança que os artistas transgredem de boa vontade, deixando aos lugares de exposição a responsabilidade de resolver tais incompatibilidades. A íntima relação entre o desenvolvimento de competências internas às estruturas e às práticas de criação aparece tão logo nos voltamos para os agentes invisíveis que detêm as informações relativas à relação entre a obra e seu meio ambiente institucional. (BENGHOSI e PARIS, 2013, p. 273)

Mas o que ocorre quando normas e valores sociais colidem com a suposta autonomia dos mundos da arte contemporânea? Até onde os agentes envolvidos com o contexto de manutenção da obra podem produzir "adequações" no espaço expositivo sem ferir a autonomia de criação artística? Como tem reagido o campo da arte brasileiro a impasses que se desenham não mais como exclusivamente estéticos, mas também de ordem ética e política?

\section{Circuito de tensões: autonomia artística versus normatização política}

No contexto de tensões que pautaram o cenário político-ideológico brasileiro nos anos 2000, não são discursos universalizantes, mas aqueles específicos do campo das artes que têm mobilizado manifestações públicas contra ou a favor de obras, artistas e instituições, cujas propostas "polêmicas" ganharam ampla repercussão nas mídias em todo o território nacional. Instados a se posicionar, justificando opções por forma e conteúdo das obras, diferentes agentes e instâncias reivindicam a suposta autonomia artística como esteio das mostras realizadas.

Nestes casos, percebe-se que apesar de "o curador de exposições ter adquirido uma autoridade explícita sobre a organização do espaço expositivo... o artista continua a deter autoridade moral sobre a obra”. (BENGHOSI \& PARIS, 2013, p. 274). Porém, é preciso considerar que a prática de tomada de posição por parte de artistas brasileiros, como formadores de opinião, enredados em lutas políticas não é fato absolutamente novo.

Se tais manifestações são especialmente visíveis em tempos de guerra, diversas áreas e formas de expressão artísticas fizeram-se presente no cenário público brasileiro, a partir da primeira metade do século XX, a exemplo das contribuições que culminaram com a Semana de Arte Moderna de 1922. Do mesmo modo, a partir dos anos 60, diversos domínios do campo da arte mobilizaram-se, valendo-se da relativa autonomia desse campo para denunciarem em obras de efeito contundente a restrição de liberdades individuais, representada pelo regime ditatorial no Brasil.

No período do governo militar (1964 1985), em que a intelectualidade artística atuava nas telenovelas, na música, no ci- 
nema, na produção plástica e fotográfica, na publicidade e no jornalismo, foi preciso enfrentar diversos modos de cerceamento às liberdades individuais por parte do Estado. No período pós-ditadura, ínterim historicamente designado de redemocratização, conceitos tais como os de cidadania, democracia, responsabilidade social, direitos humanos e liberdade de expressão, passaram a movimentar a agenda nacional, em sincronia com os discursos libertários que integravam o debate global pós Maio de 68.

Tal cenário serviu de leitmotiv para reelaborar os contornos da produção intelectual brasileira, a qual passa a refletir sobre o lugar que os artistas deveriam ocupar socialmente, não apenas em períodos caracterizados por regimes de exceção, mas também no delineamento do espaço público em regimes democráticos. De fato, nestes os problemas relativos à convivência entre diferentes perspectivas políticas são por vezes menos evidentes, pois:

... já não há inimigo global, rival planetário (como dizia-se haver durante a Guerra Fria). Em contraposição, a democracia produz, nela mesma, forças que a ameaçam, e a novidade de nossos tempos é que essas forças são superiores àquelas que a atacam de fora. Combatê-las e neutralizá-las é tanto mais difícil quanto mais elas invocam o espírito democrático e possuem, assim, as aparências da legitimidade (TODOROV, 2012, p. 14).

Plenamente reconfigurado o momento de redemocratização das instituições políticas brasileiras após a ascensão do Partido dos Trabalhadores (PT) ao poder, as perspectivas totalitárias pareciam terem tornado-se menos uma ameaça e mais a expressão de uma vontade política anacrônica. Porém, no contexto da abertura às possibilidades de usufruto do direito de livre expressão, da ocupação do espaço e do discurso públicos, o campo das artes no Brasil deparou-se com interdições de diversas ordens.

Assim, sob o pretexto da defesa dos interesses da "soberania do povo" (de seus valores, crenças e tradições), setores conservadores opuseram-se ao exercício indiscriminado da "liberdade da pessoa" (no caso, dos artistas). No curso da segunda década do século XXI, o confronto de diferentes formas de autonomia fez ecoar fatos de uma memória social não completamente superada, cuja marca era a da tentativa de silenciamento imposto à intelectualidade e às expressões artísticas no Brasil.

Paradoxalmente alinhada ao discurso libertário, essa cruzada político-messiânica, a qual ganhou dimensões globais e tonalidades locais, passou a combater violentamente e de forma preventiva a ameaça representada por questões como a legalização do aborto, o casamento entre pessoas do mesmo sexo e a pena de morte. Paralelamente, as redes sociais favoreceram a difusão de expressões de ódio associadas a certo moralismo comportamental. Assim, por meio da convergência entre as esferas da política e da religião, assiste-se ao fortalecimento da chamada "onda conservadora” em oposição ao modelo político forjado por forças "progressistas" ou pela tradição de pensamento "de esquerda".

Nesse contexto, assiste-se à insurgência do segmento artístico às regras e valores heterônomos emanados de sistemas simbólicos estruturados, a exemplo daquele formulado pela religião (de base católica, mas também evangélica e islâmica). No Brasil, este confronto com os inimigos intimos da democracia (TODOROV, 2012) envolveu diferentes agentes e instituições, levando ao questionamento dos limites da autonomia de criação artística. 
Caminhando com léxico próprio, os artistas brasileiros engajaram-se na construção de projetos criadores que idealmente acompanhariam conquistas coletivas nos campos social e cultural, as quais supostamente manter-se-iam no regime democrático da chamada liberdade de expressão. No entanto, aos intelectuais do campo da arte caberia, talvez, a prudência de considerar que, no cerne de regimes democráticos estruturados em sociedades complexas, a tarefa da política é a de "reconciliar os interesses divergentes dos diferentes elementos da sociedade, propondo compromissos razoáveis para uns e para outros; seus objetivos são relativos, não absolutos”. (TODOROV, 2012, p. 37)

De fato, os episódios que reacenderam a ameaça à licença criadora envolveram não apenas agentes envolvidos diretamente com as dinâmicas do campo artístico, mas também mobilizaram representantes das mídias e do poder judiciário brasileiro. Como suporte aos conceitos e às reflexões conduzidas nesse artigo, serão abordados três casos ocorridos durante o ano de 2017 em algumas das programações de equipa- mentos culturais das cidades de FortalezaCE, Porto Alegre-RS e Campo Grande-MS.

Frente a tais acontecimentos, os principais canais de mídia têm investido nos recursos comunicacionais de que dispõem, replicando-os por meio da capilaridade dos canais secundários e das mídias alternativas. Tal procedimento tem gerado disputas e acirramento político, bem como estímulo ao consumo dos produtos por eles produzidos. Assim, as mídias constituem, neste caso, um agente não negligenciável, usando a polarização político-ideológica como capital, ao tempo em que acentuam as divergências entre diversas esferas de ação social.

Desse modo, na noite de 17 de outubro de 2017, em tom de denúncia e inconformidade, as redes sociais faziam repercutir a notícia do manifesto ocorrido num dos pátios da Universidade de Fortaleza - UNIFOR, aquele que antecede o espaço de exposições mantido pela instituição. A inauguração da XIX UNIFOR Plástica trouxe como atração inesperada - um protesto (FIG. 1) em defesa da artista Simone Barreto.

FIG. 1: Protesto contra censura do trabalho da artista cearense Simone Barreto. Fonte: https://www.opovo. com.br/vidaearte/2017/10/universidade-interfere-em-desenho-de-mulheres-nuas-e-artista-cearense.html

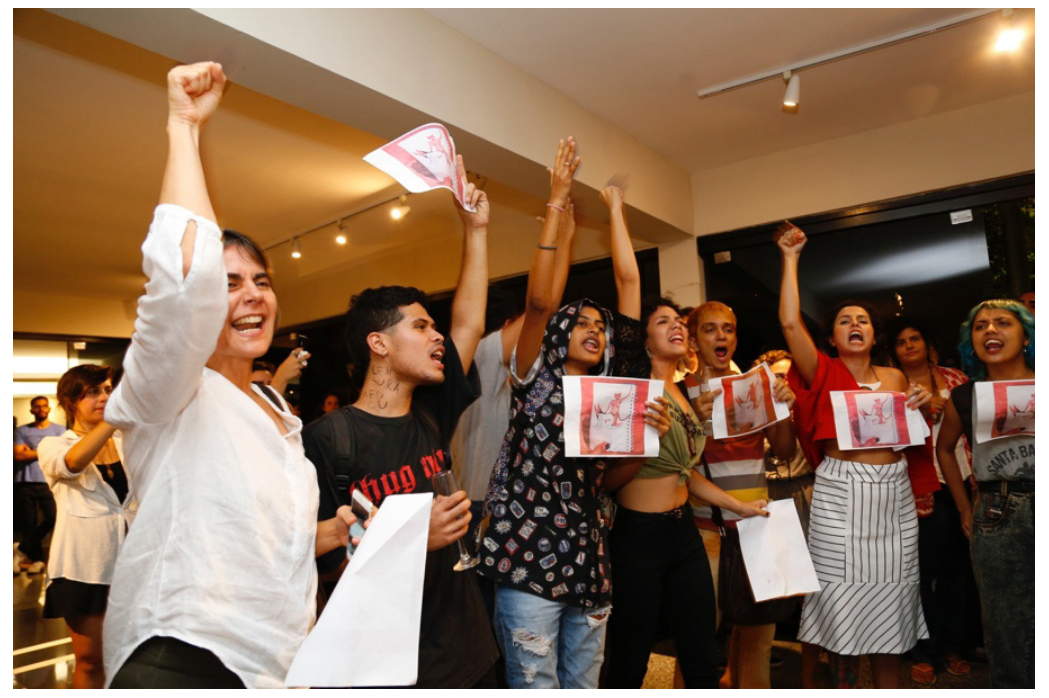


Ao jornal local, a artista expressa ter tido seu trabalho, Todas as coisas dignas de serem lembradas (FIGS. 2 e 3), impedido de ser mostrado em sua integralidade. Para a autora, como a obra criava um discurso imagético com significado, ela "(a obra) não faria sentido montada de outra forma", rebate Simone. A artista relata ter sido surpreendida na manhã do dia da inauguração do Salão com a vitrine de seus desenhos em um local "escondido" e "coberto com um pano". Em seguida, foi informada que precisaria retirar alguns desenhos para que o trabalho fosse exposto, reiterando solicitação feita alguns dias antes da abertura, a qual não fora acatada pela artista cearense.

$\mathrm{Na}$ ocasião, como forma de expressar insatisfação e fortalecer o engajamento pela garantia dos direitos de expressão do trabalho artístico, pelo menos outros dois artistas retiraram seus trabalhos da exposição em apoio a Simone Barreto. Esta ela- borou um pequeno texto como uma espécie de manifesto denunciando o ocorrido e o publicou em sua página do facebook ${ }^{2}$. Ela ainda afirmou:

Faculdade e museu são lugares de pensamento crítico, de discussão e arte (...) Mas disseram que a universidade é um lugar que recebe crianças, tirando o corpo de discussão (...) Eles disseram que eu poderia escolher outro desenho, virar a página. Para eles é muito simples, mas esse é o objeto do meu trabalho (...) É sobre esse corpo negligenciado que todo mundo já vira a página todos os dias. É um corpo que não pode ser visto, não pode ser debatido. Não é a mulher idealizada e objetificada pelo homem. É um corpo que tem sangue, pelo e cicatriz ${ }^{3}$.

Questões de gênero e desconstruções conceituais relativas ao corpo, considerado símbolo de resistência, figuraram visual-

FIGS. 2 e 3: Parte do trabalho da artista que seria exposto na mostra. Em seguida, um dos desenhos que teria sido "escondido". Fonte: https://www.opovo.com.br/vidaearte/2017/10/universidade-interfere-em-desenhode-mulheres-nuas-e-artista-cearense.html
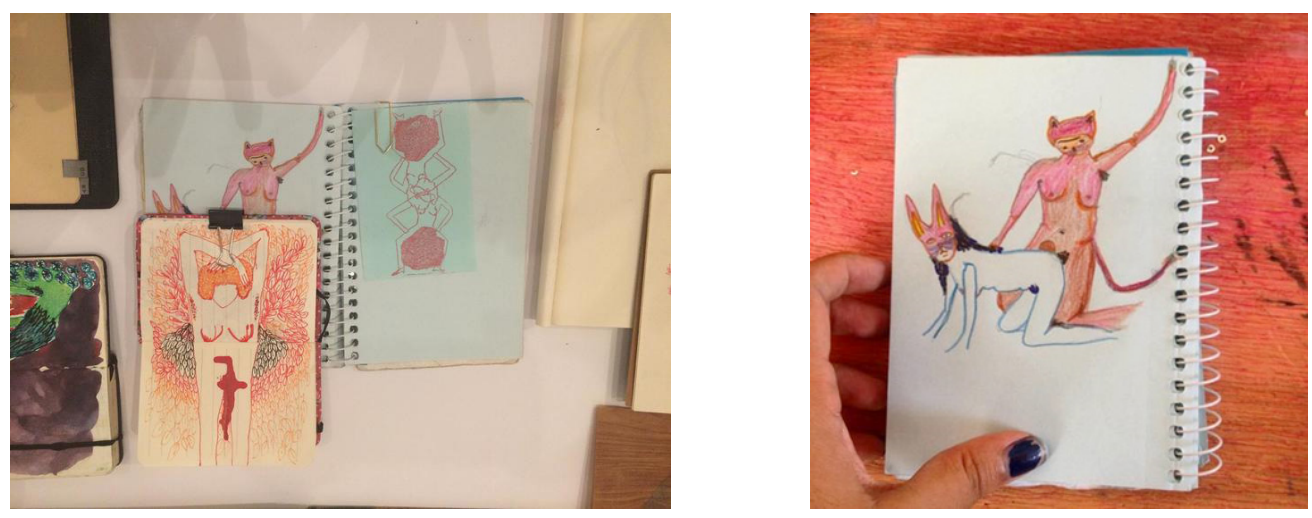

2. 0 manifesto pode ser lido em: https://www.facebook.com/photo. php?fbid=1761028557243009\&set=a.102105723135309.4566.100000076467370\&type=3\&theater 3. Relato da artista ao Jornal 0 Povo. Fonte: https://www.opovo.com.br/vidaearte/2017/10/universidadeinterfere-em-desenho-de-mulheres-nuas-e-artista-cearense.html 
mente nos desenhos impedidos. Estas são duas das principais pautas que integram o projeto criador da artista cearense, e, não por acaso, são também duas das inquirições que têm ocupado o debate da agenda nacional. Neste âmbito, para além dos citados temas, outros têm sido problematizados, a exemplo da orientação afetiva e sexual; tolerância religiosa; censura e classificação indicativa em exposições; limites da arte, para citar apenas alguns assuntos correlatos que têm protagonizado a produção discursiva dos agentes no meio intelectual brasileiro.

A influência e penetração de tais pautas junto a diversos grupos sociais, dentre os quais os artistas têm crescido proporcionalmente ao desenvolvimento das esferas democráticas que propiciam alargamento e aceitação às suas proposições. Para o Bobbio,

nas democracias modernas, pluralistas, isso se dá graças ao aumento significativo dos meios de comunicação, nos quais o poder ideológico pode se manifestar e se expandir com grande profusão. Ou seja, assim como o meio do poder político é sempre em última instância a posse das armas e o meio do poder econômico é a acumulação dos bens materiais, o principal meio do poder ideológico é a palavra, ou melhor, a expressão de ideias por meio da palavra, e com a palavra, agora e sempre mais, a imagem (BOBBIO, 1994, p. 12).

As dinâmicas criativas da nova intelectualidade, principalmente aquelas que se configuram nas práticas de artistas plásticos, na condição de intelectuais específicos, têm suas propostas estéticas associadas a comportamentos desviantes em face da cruzada moral movida por diversos grupos sociais de elevado capital financeiro. Estes, por meio da instrumentalização do discurso político-ideológico, veem como forma estratégica de reação midiatizar o escândalo que a arte engajada potencialmente traz. Por sua vez, os artistas baseiam a defesa de autonomia de criação não só nos ideais democráticos que a modernidade inaugurou e a contemporaneidade perpetrou, mas também na lógica própria que se configurou historicamente como resultado de múltiplas revoluções simbólicas no campo das artes. Sobre isso, Bourdieu afırma:

se as revoluções simbólicas são especialmente difíceis de entender, mais ainda quando são exitosas, é porque o mais difícil é entender o que parece óbvio, na medida em que a revolução simbólica produz as estruturas pelas quais a percebemos. Em outras palavras, assim como as grandes revoluções religiosas, uma revolução simbólica desarranja estruturas cognitivas e às vezes, em certa medida, estruturas sociais. Quando bem-sucedida, ela impõe novas estruturas cognitivas que pelo fato de se generalizarem, de se difundirem, de habitarem o conjunto num universo social dos sujeitos que percebem tornam-se imperceptíveis. Nossas categorias de percepção e apreciação, as que normalmente empregamos para entender as representações do mundo e o próprio mundo, nasceram dessa revolução simbólica bem-sucedida. A representação do mundo nascido dessa revolução tornou-se, assim, evidente - tão evidente que hoje o escândalo provocado pelas obras de Manet é em si mesmo objeto de espanto, senão de escândalo. Em outras palavras, assistimos a uma espécie de reviravolta (BOURDIEU, 2014, p. 122).

Partindo de tais considerações, é possível questionar se os enfrentamentos descritos revelam indícios de uma "revolução simbólica” (em termos perceptivos e cognitivos) 
que ainda não obteve êxito. Todo processo revolucionário suscita efeitos, a exemplo da tentativa de impedimento em exposições, bem como disputas discursivas para a definição da "verdade" no campo, já que os aspectos de um sistema democrático não se defınem "por um traço único, mas por um conjunto de características que se combinam para formar um arranjo complexo, em cujo seio elas se limitam e se equilibram mutuamente" (TODOROV, 2012, p. 15).

Em circunstâncias semelhantes às do caso de Simone Barreto, o Queermuseu Cartografias da Diferença na Arte Brasileira (FIG. 6), exposição coletiva fomentada pelo Santander Cultural em Porto Alegre (RS) passou por situação semelhante. Esta teve sua programação cancelada pela instituição frente à pressão causada por grupos políticos que identificaram, dentre os trabalhos que compunham a mostra, obras que supostamente promoveriam pedofilia, zoofilia, sexualização infantil (FIG. 5) e o desrespeito a símbolos religiosos (FIG. 4).

A coletiva que foi inaugurada em 15 de agosto de 2017 ficaria em cartaz até 08 de outubro. No entanto, fora encerrada em 10 de setembro do mesmo ano. A mostra com temática de diversidade sexual teve uma repercussão midiática mais ampla e capilarizada do que a exposição anteriormente analisada por ter inaugurado - pelo menos no discurso referendado pelos canais de comunicação de maior alcance nacional - os casos de obstrução das possibilidades de expor livremente trabalhos artísticos no Brasil, em especial no ano de 2017. Devido a sua temática, o debate tornou-se intenso e muitas questões foram problematizadas, nesse momento em que a grande mídia di-

FIGS. 4, 5 e 6: Em sentido horário (6, 5 e 4), um dos quadros com elementos religiosos católicos em fusão com outros símbolos e objetos; obra de Bia Leite que suscitou a discussão a respeito de prostituição infantil, levantada por grupos opositores; e o saguão da exposição no espaço cultural da instituição. Fonte: https:// veja.abril.com.br/blog/rio-grande-do-sul/veja-imagens-da-exposicao-cancelada-pelo-santander-no-rs/
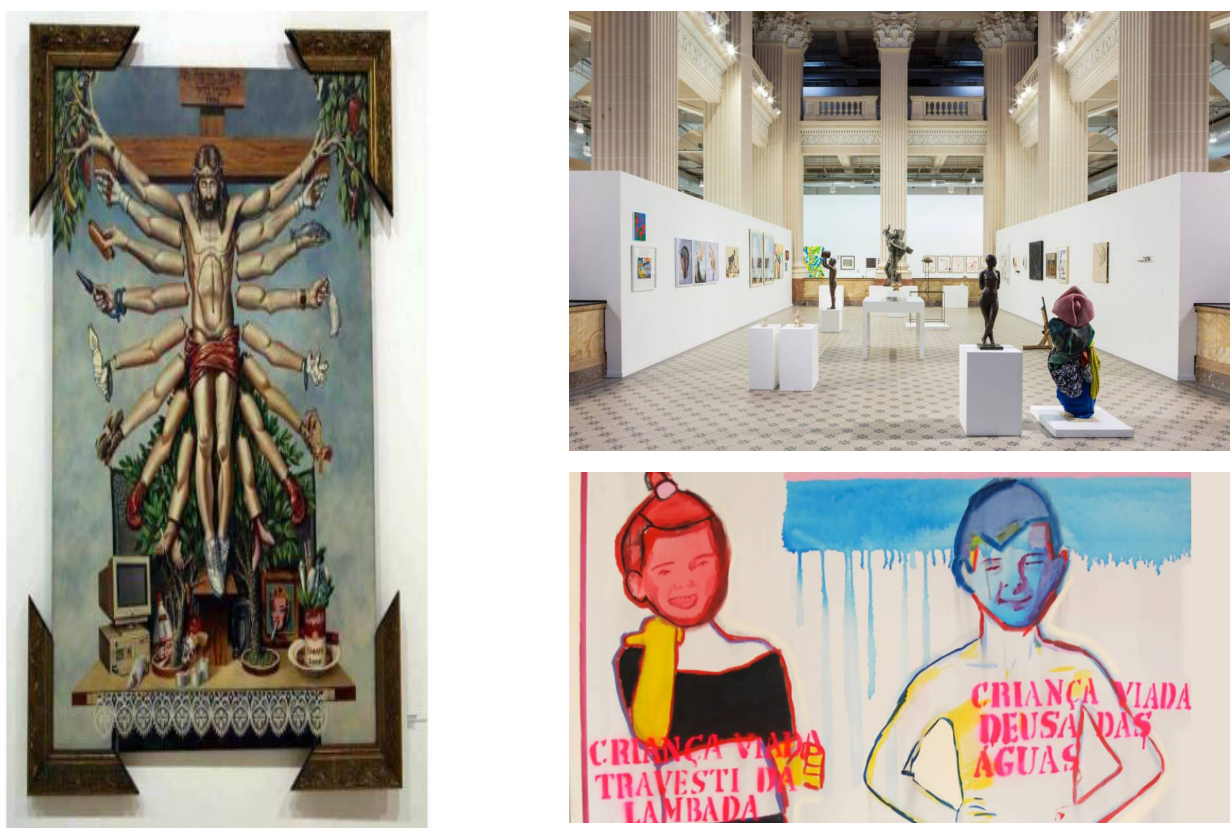
vulgou como ponto inaugural daquilo que foi denominado o "renascer do fantasma da censura no Brasil" " ou do "ano em que a censura voltou a ameaçar as artes visuais" 5 . Após o ocorrido, e devido à onda de pressões que ameaçavam de boicote a instituição financeira, a mostra foi cancelada.

Diante das causas defendidas, mediante as etapas da luta simbólica travada e as pautas abordadas no discurso formulado por agentes do campo da arte, tanto no caso do Queermuseum quanto naquele da obra Todas as coisas dignas de serem lembradas, evidencia-se a atuação do artista ativista. Assumindo o lugar do intelectual de abordagens específicas, o artista alinha-se à proposição foucaultiana do agente que atua em espaços particulares de lutas, e não mais com a formulação de juízos universalistas que fundamentam sua tomada de posição. Tal agente estaria enredado não em apontar problemas e propor soluções às massas, mas em movimentar o poder (de pensamento e ação) junto a grupos sociais específicos, gerando capital intelectual para dar substância ao debate e respaldar o processo de revolução no âmbito simbólico na arte.

Por fim, como terceiro exemplo, $\mathrm{Ca}$ dafalso (FIGS. 7 e 8), exposição da artista Alessandra Cunha, a Ropre, no Marco (Museu de Arte Contemporânea, em Mato Grosso do Sul / Brasil) gerou polêmica por apresentar desenhos de nudez, masturbação e um quadro sobre pedofilia, inclusive assim também intitulado pela própria autora.

A polícia chegou a apreender um dos quadros, em setembro de 2017, para averiguar se, de fato, fazia apologia à pedofilia ${ }^{6}$,

FIGS. 7 e 8: Parte dos quadros que compuseram a exposição Cadafalso da artista mineira Alessandra Cunha (Ropre). Fontes: http://www.obeltrano.com.br/portfolio/apos-queermuseu-quadro-sobre-pedofilia-e-censurado/ e http://www.topmidianews.com.br/cidade-morena/exposicao-que-deputados-querem-censurar-encerra-em-tres-dias/76264/
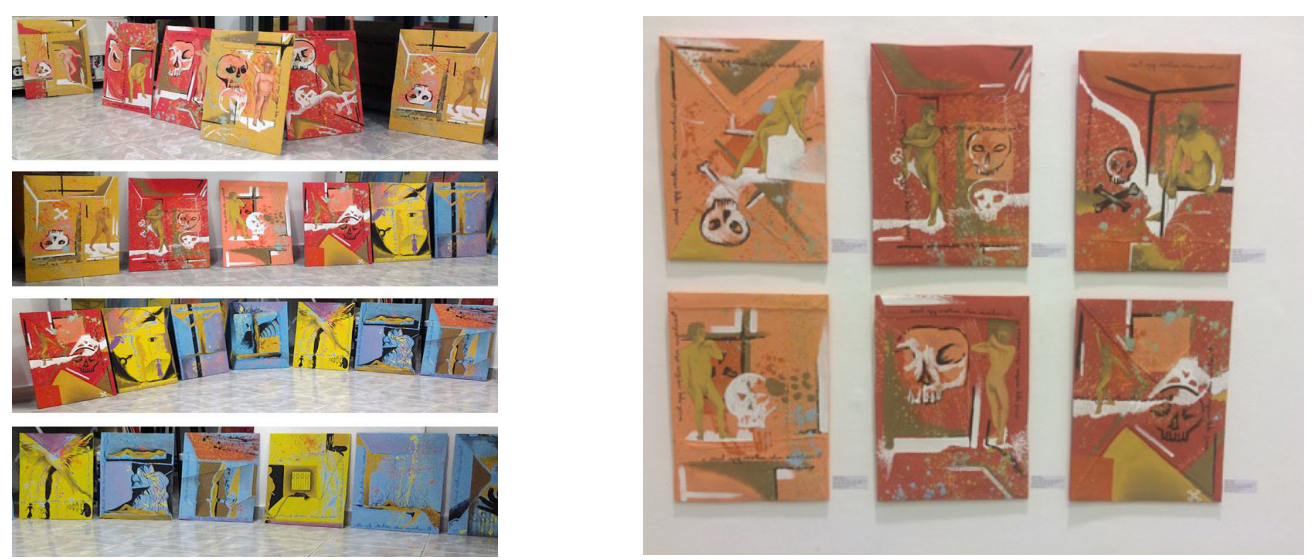

4. Fonte: https://istoe.com.br/arte-sob-a-lupa-ou-o-renascer-do-fantasma-da-censura-no-brasil/

5. Fonte: https://oglobo.globo.com/cultura/artes-visuais/2017-ano-em-que-censura-voltou-ameacar-asartes-visuais-22226423

6. Fonte: https://www.campograndenews.com.br/politica/assembleia-e-ufms-realizam-audiencia-sobrecensura-a-arte-em-ms 
mas foi devolvido ao museu no mesmo dia, mediante garantia de que a classificação etária figurasse de forma preventiva à entrada da exposição: poderia ser vista apenas por maiores de 18 anos.

0 discurso da artista aponta a ironia da situação em que se apreende uma obra realizada justamente para gerar debate e reflexões acerca de temas como o machismo e a violência sexual. Dito de outra forma, seu trabalho artístico foi elaborado para evidenciar um fato social condenável que pode ser criminalizado, mas que muitas vezes é tratado apenas com categorias moralizadoras que permeiam o pensamento social comum. Em suma, a obra foi exposta para incitar o público a tomar uma posição crítica em relação à situações de violência contra a mulher, "por isso o nome Cadafalso: local onde eram julgadas e queimadas vivas as mulheres acusadas de bruxaria pela Inquisição Católica na Idade média" , afırmou a artista, que esteve sob o risco de denúncia formal.

De manifestações de artistas, universitários e representantes do setor cultural à realização de audiência pública, o caso repercutiu não só entre os agentes do campo das artes, mas também entre aqueles que representam o poder público ${ }^{8}$.

Neste ponto, talvez fosse conveniente refletir acerca das instâncias sociais que estabelecem limites à autonomia criativa no campo das artes, tomando esta como categorial central para a manutenção do diálogo insubmisso que o artista mantém frente a pressões heterônomas. Que tipo de normatização incidiria sobre o trabalho desses intelectuais específicos que atuam no campo da arte contemporânea? Estes questionamentos parecem remeter a novos desafios impostos não só à sociologia da arte ou das profissões, mas também à sociologia política.

$\mathrm{Na}$ contemporaneidade, a reflexão sociológica sistemática, capaz de contribuir para elaboração de um olhar específico sobre o domínio empírico do campo das artes, deve admitir que os desdobramentos dos fatos relatados neste artigo e outros ocorridos desde 2017 (aqueles midiatizados, mas também os que não o foram) dizem respeito ao universo social de forma extensiva. De fato, as lutas e atos de violência simbólica evidenciados nas salas dos museus e nas aberturas de exposições têm emergido também em outros domínios e estruturas do social.

Nesses jogos de ressignificação da autonomia artística, mesmo grupos que não estão ligados ao domínio artístico e nem ao campo da intelectualidade acham-se envolvidos em um momento denso em termos de revisão de pactos que fundamentaram a vida social nas últimas décadas, revelando a disputa de valores que perpassa a configuração de cada campo de ação social.

\section{Considerações finais}

Um dos principais fatores que subjaz aos casos mencionados neste artigo diz respeito ao lugar central que as imagens ocupa-

7. Fonte: https://www.campograndenews.com.br/politica/assembleia-e-ufms-realizam-audiencia-sobrecensura-a-arte-em-ms

80 caso possibilitou "uma discussão qualificada sobre o papel das artes e a democracia, em um momento histórico de crescimento do pensamento conservador, autoritário e carregado de ódio”, comoafirma o parlamentar Pedro Kemp, deputado estadual pelo estado do Mato Grosso do Sul e filiado ao Partido dos Trabalhadores (PT). 
ram como elemento mediador em situações que cruzam os campos da arte e da política, colocando em questão a autonomia de expressão de artistas contemporâneos. De fato, pode-se problematizar tanto o papel das imagens como elemento organizador, agregador, em torno de valores e crenças, quanto seu aspecto dispersante, que compartimenta e revela dissensos.

Ricardo Campos (2013) afirma que essa sensação de que a imagem tem uma presença mais assídua na sociedade atual do que em outros tempos, deve-se talvez ao fato da proliferação de tecnologias que as produzem incessantemente, conferindo-lhe valor fundante em diversos modos de agenciamento. Do lugar ocupado pelas imagens nas religiões, nas artes, na política, nas relações de mercado, nas redes sociais, percebe-se que o impacto (e em alguns casos, o escândalo) provocado por elas remete à carga de intencionalidades da qual elas se acham investidas, tendo, por isso, função ativa nas relações sociais, como aborda Alfred Gell em Art and Agency (1998).

Contudo, a intenção do artista na produção visual insere-se sempre em contextos de recepção mais ou menos estruturados. Nos casos analisados, o projeto criador, cuja autonomia guiou a produção imagética e discursiva dos artistas, entrou em confronto com a recepção orientada por valores heterônomos, não propriamente artísticos, de viés moral, político, econômico ou religioso. No Brasil, os recentes episódios de mutilação de obras ou de suspensão de exposições em curso evidenciam um movimento concorrencial de valores e argumentos provenientes de diversos segmentos sociais, os quais disputam com a interpretação artístico-autoral o sentido legítimo da obra apresentada.

Ademais, por meio de redes que impri- mem dimensão instantânea à circulação de imagens/mensagens midiatizadas, o desdobramento das imagens artísticas expostas tem se dado por vezes mediante alteração do sentido da obra atribuído originalmente pelo artista, convertendo-se, assim, o escândalo estético pretendido em escândalo moral, religioso ou político. Assim, é provável que nos casos analisados as imagens estejam protagonizando e potencializando, como suportes simbólicos, a submissão da razão estética a lógicas do campo político.

Esse estado de insensibilidade para as formas artísticas e de hipersensibilidade para a dimensão moral evidencia, assim, um espaço social de conflitos assimétrico em torno da noção de autonomia, no qual o confronto causado por formas artísticas que provocam a reconfiguração de categorias perceptivas é secundarizado face àquele da instrumentalização dos conteúdos das obras pelo sistema comunicacional vinculado a interesses mercadológicos e políticos.

Dessa forma, em meio à exacerbação dos sentidos advinda do campo da cultura visual, o escândalo causado pelas proposições "avant-garde" na arte brasileira parecem ter causado um efeito moral e político desproporcional se compararmos os casos com situações homólogas ocorridas em meados do século passado. As próprias vanguardas europeias e seus desdobramentos no Brasil, a partir da década de 30, apontam para os traços da Revolução que arte e artistas prometeram provocar ao caminharem de encontro à possibilidade de libertação de padrões formais e temáticos do passado.

Nesse contexto, é preciso considerar as vantagens em termos de compreensão do fato social que a dimensão empírica da Sociologia oferece. No trabalho de elaboração conceitual de diversos níveis de generali- 
zação, aqueles de cunho mais concreto são forjados no confronto entre articulação teórico-metodológica e fenômenos sociais relativamente recentes. Tais fenômenos, por vezes, ainda não se encontram inteiramente delineados, a exemplo das tensões que perpassam atualmente a articulação entre arte, política e moral no Brasil. Assim, o conceito de intelectual específico emergiu não só do percurso histórico de superação dos contornos do intelectual total, mas atendeu à urgência de análise de movimentos sociais cuja especificidade e multiplicidade exigia uma competência forjada na vivência do domínio em estudo.

Nesse sentido, torna-se necessário pensar a configuração da autonomia criativa no campo da arte contemporânea no Brasil a partir das interações que se estabelecem entre os diferentes perfis de intelectual específico que se acha em jogo - o do artista, aquele do curador e/ou o do crítico de arte. Tal reflexão pretendeu esclarecer o papel assumido por cada um destes agentes nos recentes processos de confronto entre valores autônomos e valores heterônomos ao campo da arte. Nesse sentido, a mobilização ativista de artistas constituiu-se em elemento profícuo para revelar negociações e tensões entre os campos da arte e o político, fazendo emergir neste contexto diversos tipos de engajamento político que se delineiam atualmente no Brasil: aquele pelas obras (o "artivismo") e aquele que se expressa no discurso formulado pelos artistas (o ativismo).

0 espaço de um artigo é exíguo para o exame aprofundado de todos esses aspectos do problema analisado, porém, no caso brasileiro, parece evidente que o artista, em detrimento da figura do curador, tem assumido o papel mais ativo na defesa da autonomia de criação das obras. Apesar de normalmente incumbir-se da tarefa de ela- borar o conceito que subjaz à obra artística, a ausência ou secundarização do curador nos episódios abordados aponta, talvez, a priorização de compromissos com processos mercadológicos de consumo das obras artísticas em detrimento da defesa de imperativos que caracterizariam o campo artístico, a exemplo da noção de autonomia.

\section{Referências Bibliográficas}

BECKER, H. Mundos da arte. Lisboa: Livros Horizonte, 2010.

BENGHOZI, P.-J.; PARIS, T. (Orgs.). Howard Becker et les mondes de l'art. Colloque de Cerisy. Éditions de l'École Polytechnique, 2013.

BOBBIO, N. Os intelectuais e o poder: dúvidas e opções dos homens de cultura na sociedade contemporânea. São Paulo: Editora UNESP, 1997.

BOURDIEU, P. Manet: uma revolução simbólica. Pierre Bourdieu tradução de Rosa Freire d'Aguiar. Curso de 6 de Janeiro de 1999. Novos Estudos Novembro de 2014 (disponivel em http://www. scielo.br/pdf/nec/n99/0101-3300-nec-99-00121. pdf)

Manet: une révolution symbolique. Paris: Éditions Raison d'Agir / Éditions du Seuil, 2013.

As regras da arte: gênese e estrutura do campo literário. São Paulo: Companhia das Letras, 1996.

Campo intelectual e projeto criador. In: Pouillon, J. et al. (Orgs.). Problemas do estruturalismo. Rio de Janeiro: Zahar, 1968. pp. 105-45.

BUENO, M. L. Do moderno ao contemporâneo: uma perspectiva sociológica da modernidade nas artes plásticas. Revista de Ciências Sociais, v. 41, n. 1, 2010. pp. 27-47

CAMPOS, R. Introdução à cultura visual: abordagens e metodologias em Ciências Sociais. Lisboa: 
Editora Mundos Sociais, 2013.

CAUQUELIN, A. Arte contemporânea: uma introdução. São Paulo: Martins, 2005.

GELL, A. Art and agency: na anthropological theory. Oxford: Clarendon, 1998.

HEINICH, N. La sociologie de l'art. Editions La Découverte, Paris, 2001.

LAZARSFELD, P.F.; Katz, E. Personal Influence: The part played by people in the flow of man communications. Glencoe: Free Press, 1955.

; BERELSON, B.; \& GAUDET, H. The people's choice. Oxford: Duell, Sloan \& Pearce, 1944.

MCLUHAN, M. Galáxia de Gutemberg. São Paulo, Cia. Editora Nacional, 1977.

; FIORE, Q. Guerra e paz na aldeia global. Rio de Janeiro, Global/Record, 1971.

Os meios de comunicação como extensões do homem (Understanding media). São Paulo, Editora Cultrix, 1964.

RAMOS, A. D. (Org.). Sobre o ofício do curador. Porto Alegre: Zouk, 2010.

SANTAELLA, L. Por que as comunicações e as artes estão convergindo? São Paulo: Paulus, 2005.

SODRÉ, M. Reinventando a cultura: a comunicação e seus produtos. Petrópolis, Rio de Janeiro: Vozes, 1996.

TODOROV, T. Os inimigos íntimos da democracia.

São Paulo: Companhia das Letras, 2012. 


\section{RESUMO}

A volatilidade que caracteriza o exercício da autonomia artística parece acompanhar seu percurso histórico, da emergência de formas modernas às ações criadoras capitaneadas por artistas no contexto contemporâneo. Uma trama de agentes e instituições tem contribuído para suas múltiplas definições, tendo sido a parceria com o campo intelectual elemento fundamental para sua emergência. Este artigo tem por objetivo refletir acerca das atribulações desta noção e sobre o papel dos intelectuais como elemento mediador entre o campo artístico, o político, o midiático/comunicacional e o econômico. Neste jogo de ressignificações, estes também sofrem redefınições (do intelectual total ao específico), oscilando entre a atuação do crítico de arte, do curador e do próprio artista, envolvidos nos recentes episódios de questionamento da autonomia artística no Brasil.

\section{PALAVRAS-CHAVE}

Intelectuais. Política. Arte contemporânea. Autonomia. Comunicação.

\section{ABSTRACT}

The volatility that characterizes the exercise of artistic autonomy seems to follow its historical course, from the emergence of modern forms to creative actions led by artists in the contemporary context. A network of agents and institutions have contributed to its multiple definitions, and the partnership with the intellectual field has been fundamental to its emergence. This article aims to reflect on the tribulations of this notion, and the role of the intellectuals as mediating element among the artistic, political, midiatic/communicational and economic fields. In this set of resignifications, these also undergo redefinitions (from the total intellectual to the specific), oscillating between the performance of the art critic, the curator and the artist himself, involved in the recent episodes of questioning of artistic autonomy in Brazil.

\section{KEYWORDS}

Intellectuals. Politics. Contemporary Art. Autonomy. Communication. 